\title{
Analisis Karakter Remaja Gaul Pada Hedonisme Vlog
}

\author{
Sandi Saputra, Ririn Dewi Lestari, Milasari, Octarina Hidayatus Sholikhah \\ sandisaputra14141418@gmail.com
}

Prodi Pendidikan Guru Sekolah Dasar, Universitas PGRI Madiun, Madiun, Indonesia

\begin{abstract}
Penelitian ini bertujuan untuk mengetahui karakter yang ingin ditunjukkan oleh remaja gaul pada hedonisme vlog. Jenis penelitian ini adalah penelitian deskriptif kualitatif dengan metode analisis isi. Sumber data yang digunakan berupa lima vlog remaja hedonisme yang memiliki viewer terbanyak. Teknik pengumpulan data yang digunakan adalah teknik catat. Keabsahan data penelitian menggunakan triangulasi peneliti, yaitu dilakukan dengan menggunakan tiga orang peneliti dalam pengumpulan dan analisis data. Teknik analisis data menggunakan model analisis mengalir, yang meliputi tiga komponen, yaitu (1) reduksi data; (2) penyajian data; dan (3) penarikan simpulan. Hasil penelitian menunjukkan bahwa karakter-karakter yang dominan dimunculkan oleh remaja gaul pada hedonisme vlog berupa karakter ketidaksopanan, boros, sombong, dan percaya diri.
\end{abstract}

Kata kunci: hedonism; karakter; remaja; vlog

\section{Pendahuluan}

Remaja merupakan masa peralihan dari masa kanak-kanak ke masa dewasa. Masa remaja seringkali dikenal dengan fase mencari jati diri" atau fase "topan dan badai" (Ali \& Asrori, 2005). Menurut Sarwono (2012), definisi remaja untuk masyarakat Indonesia memiliki batasan umur antara 11 tahun hingga 24 tahun dan belum menikah. Pada masa ini, sebagian besar remaja mengalami ketidakstabilan dari waktu ke waktu sebagai konsekuensi dari usaha penyesuaian diri pada pola perilaku baru dan harapan sosial yang baru (Asri \& Anggriana, 2014). Remaja saat ini berada pada generasi cyber yang secara langsung maupun tidak berpengaruh pada perkembangan emosi, hubungan sosial, bahasa, nilai, moral, sikap dan lain sebagainya. Pada usia remaja, kematangan emosi individu belum stabil yang mendorong munculnya berbagai penyimpangan. Contoh bentuk penyimpangan yang terjadi saat ini yaitu senang hura-hura, senang pesta-pesta dan sebagainya sebagai nilai-nilai yang dominan dalam budaya anak muda (Sarwono, 2012).

Remaja juga cenderung ingin diakui sebagai anggota suatu kelompok atau diterima oleh lingkungan sosialnya. Misalnya dengan perilaku fanatik mengikuti tren yang dapat membuat para remaja merasa percaya diri dan diterima oleh lingkungan sosialnya. Remaja lebih banyak menghabiskan waktunya bersama dengan teman-teman sebaya, sehingga pengaruh teman-teman sebaya pada sikap, pembicaraan, minat, penampilan, dan perilaku lebih besar daripada pengaruh keluarganya. Misalnya, sebagian besar remaja mengetahui bahwa bila mereka memakai model pakaian yang sama dengan anggota kelompok popular, maka kesempatan untuk diterima menjadi anggota kelompok lebih besar (Hurlock, 1999).

Penyimpangan selanjutnya adalah perilaku konsumtif. Perilaku membeli tidak lagi dilakukan karena produk tersebut memang dibutuhkan, tetapi karena alasan-alasan lain seperti sekedar mengikuti arus mode atau hanya ingin mencoba produk baru. Salah satu faktor penyebab terjadinya penyimpangan pada remaja adalah berkembangnya media sosial yang tidak diikuti dengan kebijaksanaan dalam pemanfaatannya. Sebaliknya, sangat 
minim jumlah orang yang menyadari bahwa semua itu menimbulkan sebuah pengaruh yang begitu besar bahkan berdampak terhadap sebuah kehidupan, baik dampak positif maupun negatif. Remaja adalah generasi yang paling mudah terpengaruh oleh era globalisasi atau era modern (Kunto, 1999). Nampaknya, terdapat perbedaan nilai pada remaja zaman sekarang bila dibandingkan dengan remaja pada generasi sebelumnya. Perbedaan tersebut nampak dari kecenderungan perilaku pada remaja zaman sekarang yang dihadapkan pada gaya hidup yang cenderung konsumtif dan mengutamakan kesenangan semata (Anugrahpati, 2014).

Perkembangan teknologi kental dengan mulai bermunculannya aplikasi-aplikasi media sosial yang beragam. Media sosial adalah sebuah media online di mana para penggunanya bisa dengan mudah berpartisipasi, berbagi, dan menciptakan isi meliputi blog, jejaring sosial, Wiki, forum, dan dunia virtual. Contoh media sosial lain yang pupuler adalah Youtube, BBM, Messanger, Instagram, Facebook dan lain-lain. Media sosial ini memunculkan istilah-istilah "selfie" dan "vlog". Selfie maupun vlog dibagikan melalui media social dengan beragam tujuan. Fenomena yang sedang booming di kalangan remaja Indonesia saat ini adalah membuat $v$ log yang kemudian dibagikan lewat media sosial Youtube. Sementara itu, vlog adalah videoblogging, yang merupakan suatu bentuk kegiatan blogging dengan menggunakan medium video di atas penggunaan teks atau audio sebagai sumber media utama. Hasil video tersebut kemudian dibagikan pada media sosial Youtube.

Media sosial dapat memberikan manfaat jika digunakan sebagaimana mestinya, begitupun vlog yang diunggah di Youtube.
Vlog memang akan memberi kesan inspiratif bagi penikmatnya. Namun sebaliknya, jika pembuatan vlog kurang mengindahkan efek negatif maka akan memunculkan perilaku menyimpang. Misalnya, vlog yang sebagian besar isinya berupa pamer gaya hedonisme para remaja. Akhir-akhir ini, misalnya, media sosial dihebohkan dengan adanya vlog dua remaja yakni $\mathrm{KN}$ dan $\mathrm{AG}$ yang membagikan informasi yang tidak pantas untuk dibagikan sehingga KPAI mengambil sikap melaporkannya pada Kemenkominfo. Bukan hanya $\mathrm{KN}$ dan $\mathrm{AG}$, masih banyak remaja yang menggunakan media sosial sebagai ajang eksis. Biasanya mereka disebut sebagai "remaja gaul".

Remaja merupakan generasi muda penerus estafet kepemimpinan bangsa. Agar bangsanya baik, maka karakter generasi mudanya juga harus baik. Marcus Tulius Cicero tahun 106-43 SM, seorang cendekiawan Republik Roma pernah mengatakan bahwa, "Kesejahteraan sebuah bangsa bermula dari karakter kuat warganya". Menurut American Dictionary of the English Language (Wibowo, 2013), karakter didefinisikan sebagai kualitas-kualitas yang teguh dan khusus yang dibangun dalam kehidupan seorang, yang menentukan responnya tanpa pengaruh kondisi-kondisi yang ada. Akan tetapi, fenomena sharing hedonisme melalui vlog seperti yang dilakukan remaja tersebut adalah perbuatan yang tidak baik. Gaya hidup hedonis diartikan sebagai pola perilaku yang dapat diketahui dari aktivitas, minat, maupun pendapat yang selalu menekankan pada kesenangan hidup (Nurvitria, 2013).

Hedonisme secara sederhana merupakan satu paham yang mementingkan kesukaan dan kemewahan dalam kehidupan tanpa 
menghiraukan larangan agama dan tata susila. Melalui fenomena ini, peneliti bermaksud meneliti karakter apa yang ingin ditunjukkan remaja melalui hedonisme vlog.

\section{Metode}

\section{Jenis penelitian}

Jenis penelitian ini adalah penelitian deskriptif kualitatif dengan metode content analysis atau analisis isi. Penelitian ini mendeskripsikan atau menggambarkan apa yang menjadi masalah kemudian menganalisis dan menafsirkan data yang ada. Metode content analysis atau analisis isi yang digunakan dalam penelitian ini bertujuan untuk menelaah isi dari vlog remaja hedonisme.

\section{Partisipan penelitian}

Subjek penelitian ini adalah vlog remaja hedonisme. Subjek dipilih secara purposif berdasarkan indikator-indikator yang telah dibuat. Sumber data yang digunakan dalam penelitian ini adalah dokumen. Dokumen yang digunakan adalah lima $v$ log remaja hedonisme yang memenuhi indikator-indikator yang dibuat dan divalidasi oleh ahli.

\section{Data penelitian}

Teknik pegumpulan data yang digunakan dalam penelitian ini adalah teknik catat, menyesuaikan dengan data-datanya yang berupa video blog. Adapun langkah-langkah dalam pengumpulan data adalah sebagai berikut: (1) menonton vlog remaja hedonisme secara berulang-ulang, kemudian (2) mencatat adegan dan ucapan vlogger yang menyatakan adanya karakter yang ditunjukkan sesuai dengan indikator karakter yang telah dibuat.

\section{Analisis data}

Teknik analisis data yang digunakan dalam penelitian ini menggunakan model analisis mengalir, yang meliputi tiga komponen, yaitu (1) reduksi data; (2) penyajian data; dan (3) penarikan simpulan. Analisis model mengalir mempunyai tiga komponen yang saling terjalin dengan baik, yaitu sebelum, selama, dan sesudah pelaksanaan pengumpulan data.

\section{Reduksi data}

Pada langkah ini data yang diperoleh dicatat dalam uraian yang terperinci. Dari datadata yang sudah dicatat tersebut, kemudian dilakukan penyederhanaan data. Data-data yang dipilih hanyalah data yang berkaitan dengan masalah yang akan dianalisis, yang dalam hal ini adalah tentang karakter remaja yang dtunjukkan melalui vlog remaja hedonisme. Informasi-informasi yang mengacu pada permasalahan itulah yang dijadikan data dalam penelitian ini.

\section{Sajian data}

Pada langkah ini, data-data yang sudah ditetapkan kemudian disusun secara teratur dan terperinci agar mudah dipahami. Data-data tersebut kemudian dianalisis sehingga diperoleh deskripsi tentang karakter yang ditunjukkan oleh vlogger.

\section{Penarikan simpulan/verifikasi}

Pada tahap ini, dibuat kesimpulan tentang hasil dari data yang diperoleh sejak awal penelitian. Kesimpulan ini masih memerlukan adanya verifikasi (penelitian kembali tentang kebenaran laporan) sehingga hasil yang diperoleh benar-benar valid. Ketiga komponen tersebut saling berkaitan dan dilakukan secara terus menerus mulai dari awal, saat penelitian berlangsung, sampai akhir laporan.

\section{Keabsahan data}

Keabsahan data merupakan kebenaran 
data dari proses penelitian. Dalam mendapatkan data, penelitian ini menggunakan teknik triangulasi. Adapun triangulasi yang digunakan adalah triangulasi peneliti, yaitu dilakukan dengan menggunakan 3 orang peneliti dalam pengumpulan dan analisis data.

\section{Hasil}

Berdasarkan hasil pengamatan dan pencarian terhadap beberapa $v \log$ dengan menggunakan indikator pemilihan $v$ log remaja hedonisme yang telah divalidasi oleh ahli psikologi sosial dan bahasa, maka didapatkan 5 vlog hedon dari beberapa vlog remaja yang peneliti amati. Adapun kelima vlog itu adalah $v \log \mathrm{KN}$ yang memenuhi $90 \%$ indikator $v \log$ remaja hedon, vlog RN yang memenuhi 95\%, vlog VG memenuhi 90\%, vlog NA yang memenuhi $85 \%$, dan vlog LF yang memenuhi $90 \%$ indikator $v \log$ remaja hedonisme. Setelah mendapatkan vlog hedonisme, peneliti menganalisis karakter vlogger melalui masingmasing vlog hedonismenya, dan didapatkan hasil karakter yang ditunjukkan berupa karakter ketidaksopanan, percaya diri, sombong, dan boros.

Peneliti kemudian melakukan analisis karakter terhadap kelima vlog yang sudah divalidkan sebagai vlog penganut hedonisme. Berdasarkan hasil analisis dari ketiga peneliti, didapatkan data sebagai berikut.

\section{Vlog 1 dengan vlogger $K N$}

\section{Peneliti 1}

Dalam video pertama yang dianalisis oleh peneliti 1, maka didapatkan prosentase karakter ketidaksopanan sebesar 59\%, percaya diri sebesar $12 \%$, sombong sebesar $8 \%$, boros sebesar $12 \%$, supel sebesar $2 \%$, masa bodoh sebesar $2 \%$, indisipliner sebesar $2 \%$, dan peduli sebesar $2 \%$.

\section{Peneliti 2}

Dalam video pertama yang dianalisis oleh peneliti 2, didapatkan data yang menunjukkan prosentase karakter ketidaksopanan sebesar $40.67 \%$, supel sebesar $5.08 \%$, indisipliner sebesar $1.69 \%$, masa bodoh sebesar $3.38 \%$, peduli sebesar $8.47 \%$, sombong sebesar $13.55 \%$, boros sebesar $10.16 \%$, tahu balas budi $1.69 \%$, percaya diri $3.38 \%$, tidak sombong sebesar $5.58 \%$, dan pemurah $1.69 \%$.

\section{Peneliti 3}

Dalam video pertama yang dianalisis oleh peneliti 3, didapatkan data menunjukkan prosentase karakter boros sebesar 9.30\%, ketidaksopanan sebesar $44.19 \%$, percaya diri sebesar $2.33 \%$, peduli sebesar $9.30 \%$, interdisipliner sebesar $6.96 \%$, tidak religius sebesar $2.33 \%$, tidak sombong sebesar $6.98 \%$, ramah sebesar $9.27 \%$, sombong sebesar $7.31 \%$, dan supel sebesar $2.33 \%$.

Dari vlog pertama yang telah dianalisis, maka dapat disimpulkan bahwa karakter yang ditunjukkan oleh vlogger 1 adalah ketidaksopanan, indisipliner, peduli, sombong, boros, percaya diri, dan supel.

\section{Vlog 2 dengan vlogger $R N$}

\section{Peneliti 1}

Dalam video kedua yang dianalisis oleh peneliti 1 , selanjutnya didapatkan prosentase karakter boros sebesar $48.14 \%$, sombong sebesar 22.22\%, ketidaksopanan sebesar $14.81 \%$, masa bodoh sebesar $7.40 \%$, percaya diri sebesar $3.7 \%$, dan sopan sebesar $3.7 \%$.

\section{Peneliti 2}

Dalam video kedua yang dianalisis oleh peneliti 2, didapatkan prosentase karakter boros sebesar $66.67 \%$, tidak sabar sebesar $4.76 \%$, tidak sopan sebesar $9.52 \%$, sombong 
sebesar $14.28 \%$ dan percaya diri sebesar $4,76 \%$.

\section{Peneliti 3}

Dalam video kedua yang dianalisis oleh peneliti 3, didapatkan prosentase karakter percaya diri sebesar $7.14 \%$, boros sebesar $39.29 \%$, ketidaksopanan sebesar $14.29 \%$, dan sombong sebesar $39.29 \%$.

Dari vlog kedua yang telah dianalisis, maka karakter yang ditunjukkan oleh vlogger 2 adalah boros, percaya diri, tidak sopan, dan sombong.

\section{Vlog 3 dengan vlogger $V G$}

\section{Peneliti 1}

Video ketiga yang dianalisis oleh peneliti 1 menunjukkan prosentase karakter percaya diri sebesar $22.22 \%$, ketidaksopanan sebesar $22.22 \%$, boros sebesar $25.9 \%$, supel sebesar $7.4 \%$, masa bodoh sebesar $3.7 \%$, dan indisipliner sebesar $3.7 \%$.

\section{Peneliti 2}

Video ketiga yang dianalisis oleh peneliti 2 menunjukkan prosentase karakter mudah bergaul/supel sebesar $8 \%$, masa bodoh sebesar $8 \%$, tidak sopan sebesar $36 \%$, sombong sebesar $24 \%$, boros sebesar $16 \%$, dan percaya diri sebesar $8 \%$.

\section{Peneliti 3}

Sementara itu, video ketiga yang dianalisis oleh peneliti 3 menunjukkan prosentase karakter percaya diri sebesar $11.76 \%$, sopan santun sebesar $26.47 \%$, tahu balas budi sebesar $2.94 \%$, boros sebesar 23.53\%, ketidaksopanan sebesar 26.47\%, sombong sebesar $11.76 \%$, peduli sebesar $11.76 \%$, masa bodoh sebesar $2.94 \%$, supel sebesar $2.94 \%$, dan ramah sebesar $2.94 \%$.

Berdasarkan vlog 3 yang telah dianalisis, maka karakter yang ditunjukkan oleh vlogger 3 adalah supel, sombong, percaya diri, boros, tidak sopan, dan masa bodoh.

\section{Vlog 4 dengan vlogger $N A$}

\section{Peneliti 1}

Dalam video keempat yang dianalisis oleh peneliti 1, didapatkan prosentase karakter tidak sopan sebesar $52.94 \%$, percaya diri sebesar $18.51 \%$, supel sebesar $11.76 \%$, boros sebesar $5.88 \%$, sombong sebesar $5.88 \%$, dan indisipliner sebesar $5.88 \%$.

\section{Peneliti 2}

Dalam video keempat yang dianalisis oleh peneliti 2 menunjukkan prosentase karakter indisipliner sebesar $30.76 \%$, boros sebesar $15.38 \%$, tidak sopan sebesar $15.38 \%$, supel sebesar $15.38 \%$, tidak bertanggung jawab sebesar 7.69\%, sombong sebesar 7.69\%, dan percaya diri sebesar $7.69 \%$.

\section{Peneliti 3}

Dalam video keempat yang dianalisis oleh peneliti 3, diperoleh prosentase karakter percaya diri sebesar $15.38 \%$, ketidaksopanan sebesar 7.69\%, sombong sebesar 7.69\%, indisipliner sebesar $38.46 \%$, supel sebesar $15, .8 \%$, toleransi sebesar $7.69 \%$ dan boros sebesar $7.69 \%$.

Berdasarkan analisis terhadap vlog 4, maka karakter yang ditunjukkan oleh vlogger 4 adalah indisipliner, sombong, percaya diri, tidak sopan, supel/mudah bergaul, dan boros.

\section{Vlog 5 dengan vlogger $L F$}

\section{Peneliti 1}

Video kelima yang dianalisis oleh peneliti 1 menunjukkan prosentase karakter tidak sopan sebesar $63.15 \%$, boros sebesar $10.52 \%$, percaya diri sebesar $10.52 \%$, sombong sebesar $5.26 \%$, peduli sebesar $5.26 \%$, dan supel sebesar 5.26\%. 


\section{Peneliti 2}

Video kelima yang dianalisis oleh peneliti 2 menunjukkan prosentase karakter tidak sopan sebesar $30.43 \%$, supel sebesar $34.78 \%$, percaya diri sebesar $8.69 \%$, indisipliner sebesar $8.69 \%$, tidak bertanggung jawab sebesar 4.34\%, tidak sabar sebesar $4.34 \%$, boros sebesar $4.34 \%$, dan sombong sebesar $4.34 \%$.

\section{Peneliti 3}

Sementara itu, video kelima yang dianalisis oleh peeliti 3 menunjukkan prosentase karakter ketidaksopanan sebesar $59.09 \%$, peduli sebesar $4.54 \%$ indisipliner sebesar $4.54 \%$, supel sebesar $4.54 \%$, percaya diri sebesar $4.54 \%$, boros sebesar $4.54 \%$, tidak bertanggung jawab sebesar $4.54 \%$, dan sombong sebesar $4.54 \%$.

Dengan demikian, dapat disimpulkan bahwa karakter yang ditunjukkan oleh vlogger 5 pada vlog 5 adalah ketidaksopanan, supel, percaya diri, boros, dan sombong.

\section{Diskusi}

Berdasarkan dari kelima vlog yang telah dianalisis, maka karakter-karakter yang ditunjukkan oleh vlogger penganut hedonisme dapat dilihat dalam Tabel 1. Pada tabel tersebut, ditunjukkan karakter-karakter yang dimunculkan oleh setiap vlogger melalui vlog hedonnya masing-masing. Beberapa karakter yang muncul di suatu vlog memiliki kesamaan dengan karakter yang muncul di vlog lainnya.

Karakter ketidaksopanan muncul pada kelima $v \log$ hedon yang menjadi target analisis yaitu vlog ke-1, ke-2, ke-3, ke-4, dan ke-5. Karakter indisipliner muncul pada vlog ke-2 (RN) dan vlog ke-4 (NA). Karakter peduli muncul pada vlog ke-1 yaitu vlog $\mathrm{KN}$. Karakter sombong, boros, dan percaya diri muncul pada kelima vlog yang dianalisis.
Karakter masa bodoh muncul pada vlog ke-3 yaitu vlog VG. Sementara itu, karakter supel muncul pada vlog ke-1, ke-3, ke-4, dan ke-5.

Tabel 1

Karakter yang Muncul dari Lima Vlog Hedonisme

\begin{tabular}{lllllllll}
\hline Vlog & \multicolumn{10}{c}{ Karakter yang muncul } \\
\cline { 2 - 8 } ke- & K & I & P & S & B & Pc & M & Sp \\
\cline { 2 - 8 } 1 & $\sqrt{ }$ & $\sqrt{ }$ & $\sqrt{ }$ & $\sqrt{ }$ & $\sqrt{ }$ & $\sqrt{ }$ & & $\sqrt{ }$ \\
2 & $\sqrt{ }$ & & & $\sqrt{ }$ & $\sqrt{ }$ & $\sqrt{ }$ & & \\
3 & $\sqrt{ }$ & & & $\sqrt{ }$ & $\sqrt{ }$ & $\sqrt{ }$ & $\sqrt{ }$ & $\sqrt{ }$ \\
4 & $\sqrt{ }$ & $\sqrt{ }$ & & $\sqrt{ }$ & $\sqrt{ }$ & $\sqrt{ }$ & & $\sqrt{ }$ \\
5 & $\sqrt{ }$ & & & $\sqrt{ }$ & $\sqrt{ }$ & $\sqrt{ }$ & & $\sqrt{ }$ \\
\hline
\end{tabular}

Keterangan:

$\mathrm{K}=$ Ketidaksopanan; I=Indisipliner; $\mathrm{P}=$ Peduli; $\mathrm{S}=$ Sombong; $\mathrm{B}=$ Boros; $\mathrm{Pc}=$ Percaya diri; $\mathrm{M}=$ Masa bodoh; $\mathrm{Sp}=$ Supel

Karakter ketidaksopanan muncul pada kelima vlog hedon yang menjadi target analisis yaitu vlog ke-1, ke-2, ke-3, ke-4, dan ke-5. Karakter indisipliner muncul pada vlog ke-2 (RN) dan vlog ke-4 (NA). Karakter peduli muncul pada vlog ke-1 yaitu vlog $\mathrm{KN}$. Karakter sombong, boros, dan percaya diri muncul pada kelima vlog yang dianalisis. Karakter masa bodoh muncul pada vlog ke-3 yaitu vlog VG. Karakter supel muncul pada vlog ke-1, ke-3, ke-4, dan ke-5.

Berdasarkan deskripsi-deskripsi di atas, maka muncul beberapa karakter yang selalu ada/ditunjukkan di setiap vlog remaja penganut hedonisme yaitu karakter ketidaksopanan, boros, sombong, dan percaya diri. Akan tetapi, karakter yang paling mendominasi dari kelima vlog hedonisme yang diteliti yaitu ketidaksopanan dan boros.

Karakter remaja hedon yang cenderung boros ditunjukkan di setiap vlog yang dianalisis. Hal ini sejalan dengan apa yang diungkapkan oleh Wagner (2009) yang menyatakan bahwa kelompok usia remaja 
adalah salah satu pasar yang potensial bagi produsen. Alasannya antara lain karena pola konsumsi seseorang terbentuk pada usia remaja. Di samping itu, gaya hidup remaja biasanya meniru teman, tidak realistis, dan cenderung boros dalam menggunakan uangnya. Lewat gaya hidup, seorang remaja juga dapat menunjukkan citra diri dan status sosialnya di tengah-tengah masyarakat. Sifatsifat remaja inilah yang dimanfaatkan oleh sebagian produsen untuk memasuki pasar remaja.

Selain itu, Sari (2016) dalam penelitiannya yang berjudul "Kecenderungan Perilaku Compulsive Buying (Pembelian Kompulsif) pada Masa Remaja Akhir di Samarinda" menyimpulkan bahwa perilaku compulsive buying menimbulkan beberapa dampak di antaranya menambah kepercayaan diri, kepuasan diri, penyesalan, boros, berhutang, mendapat teguran, dan mencuri barang orang lain. Seperti yang kita ketahui bahwa compulsive bullying merupakan salah satu dampak buruk konsumerisme atau pembelian yang berlebihan atau pemborosan sehingga masuk pada salah satu kriteria hedonisme.

Gaya hidup hedonisme yang mereka lakukan juga dinilai mampu meningkatkan kepercayaan diri mereka. Menurut Feirst dan Feirst (2012), kurangnya percaya diri adalah kurangnya keyakinan diri dan kepercayaan diri secara ekstrim yang diungkapkan dengan rasa malu dan ragu untuk mengekspresikan diri sendiri. Remaja memiliki nilai-nilai dominan dalam budaya yaitu keunggulan dalam olahraga, pandai dansa, punya mobil, disenangi teman-teman, senang hura-hura, senang pesta-pesta, jadi teman kencan yang baik, tidak dicap pengecut, dan sebagainya. Dalam vlog yang diteliti, gaya hedon yang muncul antara lain clubbing, pesta-pesta, makan di café dan traveling. Gaya hidup hedonisme yang mereka lakukan menjadi cara meningkatkan rasa percaya diri dalam diri mereka.

Sementara itu, karakter ketidaksopanan terlihat dari ucapan-ucapan vlogger yang menggunakan kata-kata jorok, tidak baik, atau tidak sopan, seperti ungkapan "anjing loe", "anjirrr", dan lain-lain. Ketidaksopanan ini rupanya muncul pada kelima vlog yang dianalisis. Ketidaksopanan dalam konteks berpakaian juga terjadi, misalnya menggunakan pakaian-pakaian terbuka dan yang paling dominan adalah penggunaan kata kasar, jorok, dan tidak baik. Lickona (2013) mengatakan bahwa salah satu bentuk penyimpangan remaja saat ini adalah penggunaan bahasa yang tidak baik. Menurut Majid (2012), dalam perkembangan masyarakat modern saat ini, di kota-kota besar bahkan berkembang pesat bahasa khas remaja yang sering dikenal bahasa gaul. Penggunaan bahasa-bahasa yang tidak baik, kata-kata kotor, dan ketidaksopanan dalam berpakaian semuanya ditemukan di analisis ketiga peneliti.

Selain itu, karakter sombong juga turut ditunjukkan di setiap vlog hedon yang diteliti. Karakter sombong ini di antaranya adalah vlogger memamerkan barang-barang mewah yang dimiliki atau membanggakan eksistensi melalui jumlah followers akun media sosialnya. Di samping itu, vlogger juga memamerkan kegemaran mereka mengunjungi cafe-cafe untuk berkumpul dengan teman-temannya Berdasarkan hasil analisis, maka dapat disimpulkan bahwa karakter yang ditunjukkan oleh remaja gaul pada vlog hedonisme adalah ketidaksopanan, boros, sombong, dan percaya diri. 


\section{Daftar Pustaka}

Ali, M., \& Asrori, M. (2005). Psikologi Remaja Perkembangan Peserta Didik. Jakarta: Bumi Aksara.

Anugrahpati, R. D. S. (2014). Gaya hidup shopaholic Sebagai bentuk perilaku konsumtif pada kalangan mahasiswa. Skripsi. Fakultas Ilmu Sosial Universitas Negeri Yogyakarta.

Asri, D. N., \& Anggriana, T. M.. (2014). Perkembangan Peserta Didik. Madiun: IKIP PGRI Madiun.

Feirst, J., \& Feirst, G. J. (2012). Teori Kepribadian. Terjemahan oleh Hardianto. Jakarta: Salemba Humanika.

Hurlock, E. B. (1999). Psikologi Perkembangan Suatu Pendekatan Sepanjang Rentang Kehidupan. Terjemahan oleh Istiwidayanti \& Sudjarno. Jakarta: Erlangga.

Kunto, A. A. (1999). Remaja Tentang Hedonisme: Kecil Bahagia, Muda FoyaFoya, Tua Kaya Raya, Mati Masuk Surga. Yogyakarta: Kanisius

Lickona, T. (2013) Educating for Character: Mendidik untuk Membentuk Karakter. Terjemahan oleh Juma. Jakarta: Bumi Aksara.

Majid, A. (2012). Pendidikan Karakter Perspektif Islam. Bandung: Remaja Rosdakarya.

Nasution, I. K. (2007). Stress pada remaja. Skripsi. Fakultas Kedokteran. Universitas Sumatera Utara Medan.

Nurvitria, A. L. (2015). Pengaruh gaya hidup hedonis terhadap perilaku pembelian impulsif pada mahasiswa. Skripsi. Fakultas Ilmu Pendidikan UNY
Yogyakarta.

Sarwono, S. W. (2012). Psikologi Remaja. Jakarta: Raja Grafindo Persada.

Sari, R. K. (2016). Kecenderungan perilaku compulsive buying (pembelian kompulsif) pada masa remaja akhir di Samarinda. Psikoborneo, 4(3), 612-620.

Sihotang, A. (2009). Hubungan antara konformitas terhadap kelompok teman sebaya dengan pembelian impulsif pada remaja. Tesis. Fakultas Psikologi Universitas Diponegoro Semarang.

Wagner. (2009). Gaya hidup "shopping mall" sebagai bentuk perilaku konsumtif pada remaja di perkotaan. Skripsi. Fakultas Ekologi Manusia IPB Bogor.

Wibowo, A. (2013). Pendidikan Karakter di Perguruan Tinggi. Yogyakarta: Pustaka Pelajar. 